\title{
СРАВНИТЕЛЬНАЯ ОЦЕНКА ВЛИЯНИЯ ВИРДЖИНИАМИЦИНА И ПРОБИОТИКА НА СОСТАВ КИШЕЧНОГО МИКРОБИОМА И ЗООТЕХНИЧЕСКИЕ ПОКАЗАТЕЛИ ЦЫПЛЯТ-БРОЙЛЕРОВ (Gallus gallus L.)
}

\author{
Д.Г. ТЮРИНА', Г.Ю. ЛАПЕВ1, Е.А. ЙЫЛДЫРЫМ' ${ }^{凶}$, Л.А. ИЛЬИНА',
} В.А. ФИЛИППОВА ${ }^{1}$, Е.А. БРАЖНИК 1 , Н.В. ТАРЛАВИН ${ }^{1}$, Е.П. ГОРФУНКЕЛЬ ${ }^{1}$, А.В. ДУБРОВИН ${ }^{1}$, Н.И. НОВИКОВАํㅛ, Т.П. ДУНЯШЕВ ${ }^{1}$, А.А. ГРОЗИНА ${ }^{2}$

На сегодняшний день существует большой интерес к разработке кормовых экологически безопасных добавок для птицеводства, способных положительно модулировать состав микробиоты и контролировать патогенные микроорганизмы, представляя собой достойную альтернативу антибиотикам. Однако очень мало работ посвящено сопоставлению действия пробиотиков и антибиотиков на структуру микробиома кишечника у бройлеров. В настоящем исследовании мы сравнили состав микробиоты кишечника и зоотехнические показатели у цыплят кросса Cobb 500 в стартерный, ростовой и финишный периоды при добавлении в рацион пробиотика (Bacillus subtilis в coставе Целлобактерина $\left.{ }^{\circledR}-\mathrm{T}\right)$ или антибиотика (Stafac ${ }^{\circledR} 110$ на основе вирджиниамицина) и показали, что штамм B. subtilis ускоряет становление кишечной микрофлоры. Пробиотик также снижает численность микроорганизмов семейства Campylobacteriaceae, к которому относятся многие виды возбудителей гастроэнтеритов, и повышает переваримость клетчатки. Структуру микробиома в содержимом слепых отростков кишечника изучали методами количественной ПЦР и T-RFLP (terminal restriction fragment length polymorphism) анализа. У цыплят в возрасте 14 сут общая численность бактерий в химусе слепой кишки при введении в рацион антибиотика Stafac ${ }^{\circledR} 110$ была выше в 9,1 раза $(\mathbf{p} \leq \mathbf{0 , 0 5})$, B. subtilis - в 54,2 раза $($ p $\leq 0,001)$ по сравнению с контролем, что указывает на быструю колонизацию микрофлорой желудочно-кишечного тракта у особей из опытных групा. Результаты T-RFLP-анализа показали, что микрофлора в химусе слепых отростков кишечника цыплят на уровне филумов была представлена двумя доминирующими таксонами - Firmicutes и Proteobacteria, в меньшей степени - филумами Actinobacteria, Bacteroidetes и Fusobacteria. Были выявлены таксоны, которые играют важную роль в переваривании некрахмалистых полисахаридов, связанных с синтезом короткоцепочечных жирных кислот, в вытеснении патогенной микрофлоры благодаря продукции бактериоцинов, а также в снижении рН химуса вследствие синтеза органических кислот. Введение в рацион кормового антибиотика оказало преимущественно позитивное влияние на структуру микробиома: возросла доля целлюлозолитических форм и бактерий класса Clostridia (p $\leq \mathbf{0 , 0 5 )}$, участвующих в синтезе органических кислот. Сходные позитивные изменения в микробном сообществе отмечали и при интродукции пробиотического штамма $\mathrm{B}$. subtilis, в частности, по сравнению с контролем повышалось обилие бактерий класса Clostridia (p $\leq 0,05)$. На 14-е сут выращивания применение антибиотика и интродукция пробиотического штамма снизили численность микроорганизмов семейства Campylobacteriaceae $(\mathrm{p} \leq \mathbf{0 , 0 5})$, включающего многие патогенные виды. У 36-суточных курочек, в рацион которых вводили антибиотик Stafac ${ }^{\circledR} 110$, отмечено увеличение живой массы (с 1845,8 $\pm 20,9$ до 1936,4 $\pm 17,9$ г, p $=0,046)$. У пробиотического штамма бактерий подобного эффекта не наблюдали (несмотря на восстановление микрофлоры слепых отростков кишечника). Переваримость клетчатки в группе, получавшей штамм $\boldsymbol{B}$. subtilis, повышалась по сравнению с контролем на $7,1 \%(p=0,0027)$, кормовой антибиотика - на $2,3 \%$ $(p=0,047)$, что может быть связано с деятельностью целлюлозолитической микрофлоры. Таким образом, введение в рацион цыплят-бройлеров пробиотического штамма бактерий $B$. subtilis с целью восстановления микрофлоры и повышения переваримости клетчатки может быть эффективной альтернативой применению кормового антибиотику Stafac ${ }^{\circledR} 110$ на основе вирджиниамицина.

Ключевые слова: цыплята-бройлеры, Cobb 500, пробиотик, Bacillus subtilis, Stafac ${ }^{\circledR} 110$, T-RFLP-анализ, микробиом, Firmicutes, Proteobacteria, Clostridia, Campylobacteriaceae.

Широкое использование антибиотиков в животноводстве и птицеводстве приводит к появлению патогенных бактерий, устойчивых к антимикробным препаратам, что серьезно угрожает здоровью животных и человека $(1,2)$. В 2016 году Генеральная Ассамблея ООН признала использование антибиотиков в животноводстве и птицеводстве одной из основных причин резистентности к противомикробным препаратам у людей (United Nations meeting on antimicrobial resistance, 2016) (3). В Европейском союзе 
использование антибиотиков было запрещено в 2006 году, в США в Центре ветеринарной медицины Управления по контролю за продуктами и лекарствами (Center for Veterinary Medicine, Food and Drug Administration, FDA) в 2012 году было подготовлено Руководство для промышленности (FDA Guidance for Industry), в котором рекомендуется использовать антибиотики исключительно в лечебных целях в течение ограниченных периодов при вспышках инфекционных заболеваний (4). В последние годы в России в птицеводстве антибиотики широко использовались для массовой профилактики заболеваний и стимуляции роста птицы, однако с 2020 года государством установлен запрет на использование противомикробных препаратов, предназначенных для ветеринарного применения, не в лечебных целях.

Микробиом желудочно-кишечного тракта (ЖКТ) птицы играет жизненно важную роль в переваривании и усвоении питательных веществ кормов, становлении иммунитета, устойчивости к заболеваниям, расщеплении токсинов (5). Нарушения микробного сообщества ЖКТ могут неблагоприятно повлиять на эффективность кормления, продуктивность и здоровье птицы (6). Доказано $(7,8)$, что антибиотикотерапия нередко вызывает изменение структуры микробных консорциумов, провоцируя дисбактериозы с последующими физиологическими и метаболическими нарушениями в организме хозяина. Нарушение микробиоты у цыплят-бройлеров часто ассоциируется с атрофией ворсинок, уменьшением толщины оболочки мышц и увеличением инфильтрации Т-лимфоцитов в слизистой оболочке кишечника (9).

В последнее десятилетие интерес к разработке кормовых экологически безопасных добавок, способных положительно модулировать микробиоту, контролируя патогенные микроорганизмы, постоянно растет (10-12). Описаны позитивные эффекты пробиотических штаммов микроорганизмов и пребиотиков при профилактике и лечении желудочно-кишечных нарушений у цыплят-бройлеров, зараженных Clostridium perfringens (13), Campylobacter jejuni (14), Salmonella sp. (15).

Антибиотикотерапия и в особенности неконтролируемый прием антибиотиков отрицательно влияют на состав микробиоты кишечника человека (15-17). Так, доказано негативное влияние на состав микробиома человека $\beta$-лактамной терапии (16). Применение $16 \mathrm{~S}$ рДНК- и $16 \mathrm{~S}$ рРНК-секвенирования показало, что через 14 сут терапии наступает коллапс микробного биоразнообразия. Аналогичные данные получены для некоторых сельскохозяйственных животных. Например, у коров, получавших в течение 14 сут пенициллин (4,8 г на животное) и стрептомицин (5,0 г на животное), происходили нарушения в микробиоме рубца (18). Через 3 сут применения антибиотиков в рубце уменьшилось обилие 45 высокоуровневых таксонов, после 14 сут -43 таксонов.

В отношении цыплят-бройлеров аналогичные сведения ограничены. Сообщалось (19), что численность Lactobacillus spp. в подвздошной кишке цыплят, корм которых содержал тилозин и бактериостатик, значительно ниже, чем у не получавших тилозин. Подобные эффекты описаны в других исследованиях (20-22). Однако очень мало работ посвящено сравнению действия пробиотиков и антибиотиков на состав микробиома кишечника у бройлеров (23).

В представленном исследовании мы показали, что при интродукции штамма Bacillus subtilis в желудочно-кишечный тракт цыплят-бройлеров становление кишечной микрофлоры происходит быстрее (начиная с 1-х сут жизни), чем при добавлении в корм антибиотика Stafac ${ }^{\circledR} 110$ на основе вирджиниамицина. Пробиотик снижал обилие микроорганизмов семейства 
Campylobacteriaceae, включающего род Campylobacter, к которому относятся многие виды возбудителей гастроэнтеритов, а также повышал переваримость клетчатки и, следовательно, может быть эффективной альтернативой кормовому антибиотику $\operatorname{Stafac}^{\circledR} 110$.

Нашей целью было сравнение количественного состава микробиоты кишечника и зоотехнических показателей у цыплят в стартерный, ростовой и финишный периоды при добавлении в рацион пробиотика или антибиотика.

Методика. Цыплят кросса Cobb 500 случайным образом разделили на три группы по 70 гол. Контрольная I группа получала основной рацион полнорационные россыпные комбикорма, сбалансированные по нормам для кросса, включающие пшеницу, соевый и подсолнечный шрот, масло соевое, рыбную и мясокостную муку, известняк, монокальцийфосфат, витаминно-минеральный комплекс (содержание клетчатки в стартерный, ростовой и финишный периоды - 4 \%). Птице из II группы в рацион добавляли Stafac ${ }^{\circledR} 110$ («Phibro Animal Health Corporation», США) в дозировке 180 г/т корма. В состав Stafac ${ }^{\circledR} 110$ входит действующее вещество вирджиниамицин (11\%) и вспомогательные вещества - карбоксиметилцеллюлоза $(4,4 \%)$, карбонат кальция (11\%), минеральное масло $(0,2 \%)$, очищенные водорастворимые гранулы $(73,4 \%)$. В III группе к корму в утреннее время $\left(10^{00}\right)$ добавляли пробиотик Целлобактерин ${ }^{\circledR}-\mathrm{T}$, содержащий Bacillus subtilis (ООО «БИОТРОФ», Россия) (1 кг/т комбикорма согласно инструкции к препарату). Птицу содержали в клеточных батареях типа Р-15 (Россия) (по 35 цыплят в клетке; виварий, ФГНИУ Всероссийский научно-исследовательский ветеринарный институт птицеводства, г. Санкт-Петербург, 2014 год). Цыплятам был обеспечен свободный доступ к кормам и воде. Технологические условия соответствовали рекомендациям («Ресурсосберегающая технология производства мяса бройлеров: методические рекомендации». Загорск, 1990).

Учитывали сохранность поголовья и прирост живой массы индивидуальным взвешиванием в течение опыта (1-36-е сут жизни). Физиологический балансовый опыт по оценке переваримости и использования питательных и минеральных веществ корма проводили с 28-х по 36-е сут $(n=6)$ согласно методике научных и производственных исследований по кормлению сельскохозяйственной птицы ФГБНУ ВНИТИП (Сергиев Посад, 2013).

В каждой группе у шести цыплят - аналогов по живой массе отбирали post mortem содержимое слепых отростков кишечника (по 5-10 г) для исследования микробиоты. В возрасте 1 сут пробы отбирали через 24 ч после кормления, в 7, 14, 21 и 36 сут - у особей, имеющих заполненный зоб. Отобранные образцы немедленно помещали в центрифужные стерильные пластиковые пробирки, замораживали при $-20^{\circ} \mathrm{C}$ и доставляли в сухом льду в молекулярно-генетическую лабораторию научно-производственной компании ООО «БИОТРОФ» для выделения ДНК.

Тотальную ДНК из исследуемых образцов выделяли с использованием набора Genomic DNA Purification Kit («Fermentas, Inc.», Литва) согласно прилагаемой инструкции.

T-RFLP (terminal restriction fragment length polymorphism) анализ проводили по методике, разработанной нами ранее (24).

Для количественной ПЦР (qPCR, термоциклер ДТ Lite-4, OOO «НПО ДНК-Технология», Россия) использовали набор реактивов для проведения ПЦР-РВ в присутствии интеркалирующего красителя EVA Green (ЗАО «Синтол», Россия) согласно прилагаемым инструкциям. Применяли универсальные праймеры для определения общего числа бактерий: HDA1 - 
5' -ACTCCTACGGGAGGCAGCAG-3', HDA2 - 5'-GTATTACCGCGGCTGCTGGCA-3' (25); протокол амплификации: 3 мин при $95^{\circ} \mathrm{C}$ (1 цикл); 1 мин при $95{ }^{\circ} \mathrm{C}, 1$ мин при $57,6{ }^{\circ} \mathrm{C}$, 1 мин при $72{ }^{\circ} \mathrm{C}$ (40 циклов); 5 мин при $72{ }^{\circ} \mathrm{C}(1$ цикл).

Разнообразие бактериального сообщества оценивали графически в виде тепловой карты при помощи пакета «pheatmap» (Version: 1.0.12) для R (https://www.rdocumentation.org/packages/pheatmap/versions/1.0.12/topics/pheatmap) (26). Иерархическую кластеризацию по группам проводили по методу Уорда (Ward-linkage clustering method) на матрице, построенной по квадрату евклидовых расстояний между объектами $(27,28)$.

Для математической и статистическую обработки данных применяли программные пакеты Microsoft Office Excel 2003, R-Studio (Version 1.1.453) (https://rstudio.com), PAST (https://www.bytesin.com/software/PAST/) (29, 30). Количественные значения сравнивали с помощью $t$-критерия Стьюдента. Результаты статистического анализа считались значимыми при $\mathrm{p} \leq 0,05$. Числовые данные представлены в виде средних $(M)$ и их стандартных ошибок $( \pm$ SEM $)$.

Результаты. По нашему мнению, наибольший интерес представляют изменения, вызываемые анти- и пробиотиком в структуре микробиоты содержимого слепых отростков кишечника: именно в слепой кишке происходят основные процессы ферментации и переваривания сложных субстратов (целлюлозы, крахмалы, других полисахаридов), и удерживание корма здесь наиболее продолжительно (12-20 ч) (5). Для сравнения с антибиотиком Stafac ${ }^{\circledR} 110$ мы выбрали Целлобактерин ${ }^{\circledR}-\mathrm{T}-$ кормовую добавку со свойствами пробиотика (ТУ 10.91.10-014-50932298-2019, регистрационный номер ПВР-2-18.11/02763). В ее состав входят пшеничные отруби (ГОСТ 7169-2017), на которые нанесены микроорганизмы Bacillus subtilis.

Результаты определения численности бактерий в исследованных образцах слепых отростков кишечника цыплят-бройлеров методом количественной ПЦР представлены на рисунке 1. В зависимости от возраста и варианта опыта она составила от $2,4 \times 10^{9} \pm 4,7 \times 10^{8}$ до $1,4 \times 10^{11} \pm 7,0 \times 10^{9}$ клеток/г. Это совпадает с известными данными: сообщалось (31), что численность бактерий в слепых отростках у 1-суточных цыплят составляет от $10^{8}$ до $10^{10}$ клеток/г, достигая с возрастом значений от $10^{9}$ до $10^{11}$ клеток/г.

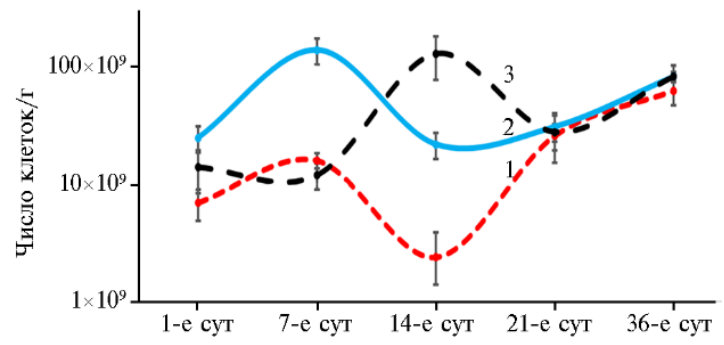

Рис. 1. Возрастная динамика общей численности бактерий в содержимом слепых отростков кишечника цыплят-бройлеров кросса Cobb 500, получавших основной рацион $(1$, контроль), при включении в рацион антибиотика $\operatorname{Stafac}^{\circledR} 110$ (2) или кормовой добавки Целлобактерин ${ }^{\circledR}-\mathrm{T}$ с пробиотическими свойствами, содержащей $\mathrm{Ba}$ cillus subtilis (3) ( $n=3, M \pm \mathrm{SEM}$, анализ методом количественной ПЦР; виварий,

ФГНИУ Всероссийский научно-исследовательский ветеринарный институт птицеводства, г. СанктПетербург, 2014 год).

В возрасте 14 сут общая численность бактерий в химусе слепой кишки в группе, получавшей антибиотик $\operatorname{Stafac}^{\circledR}$ 110, была выше в 9,1 раза $(\mathrm{p} \leq 0,05)$, пробиотик B. subtilis - в 54,2 раза $(\mathrm{p} \leq 0,001)$ по сравнению с контролем (рис. 1). Однако под влиянием антибиотика достоверное увеличение общего обилия бактерий в слепых отростках по сравнению с контролем отмечали уже в 1 -е и на 7-е сут (соответственно $\mathrm{p} \leq 0,05$ и $\mathrm{p} \leq 0,01$ ), тогда как в вариантах с $B$. subtilis разницы в эти периоды мы не обнаружили. 
Полученные результаты указывают на быструю микробную колонизацию желудочно-кишечного тракта цыплят из опытных групп (особенно при использовании антибиотика), что имеет важное значение в этот период жизни: в течение 2 нед после вылупления иммунная система цыплят еще не полностью развита, и они наиболее уязвимы для негативного воздействия патогенной микрофлоры (32). Так, известно (33), что с первых суток жизни птенцы начинают склевывать и проглатывать частички подстилки, обсемененной микроорганизмами, в том числе патогенными (Salmonella, Clostridium perfringens, Campylobacter jejuni, Escherichia coli).

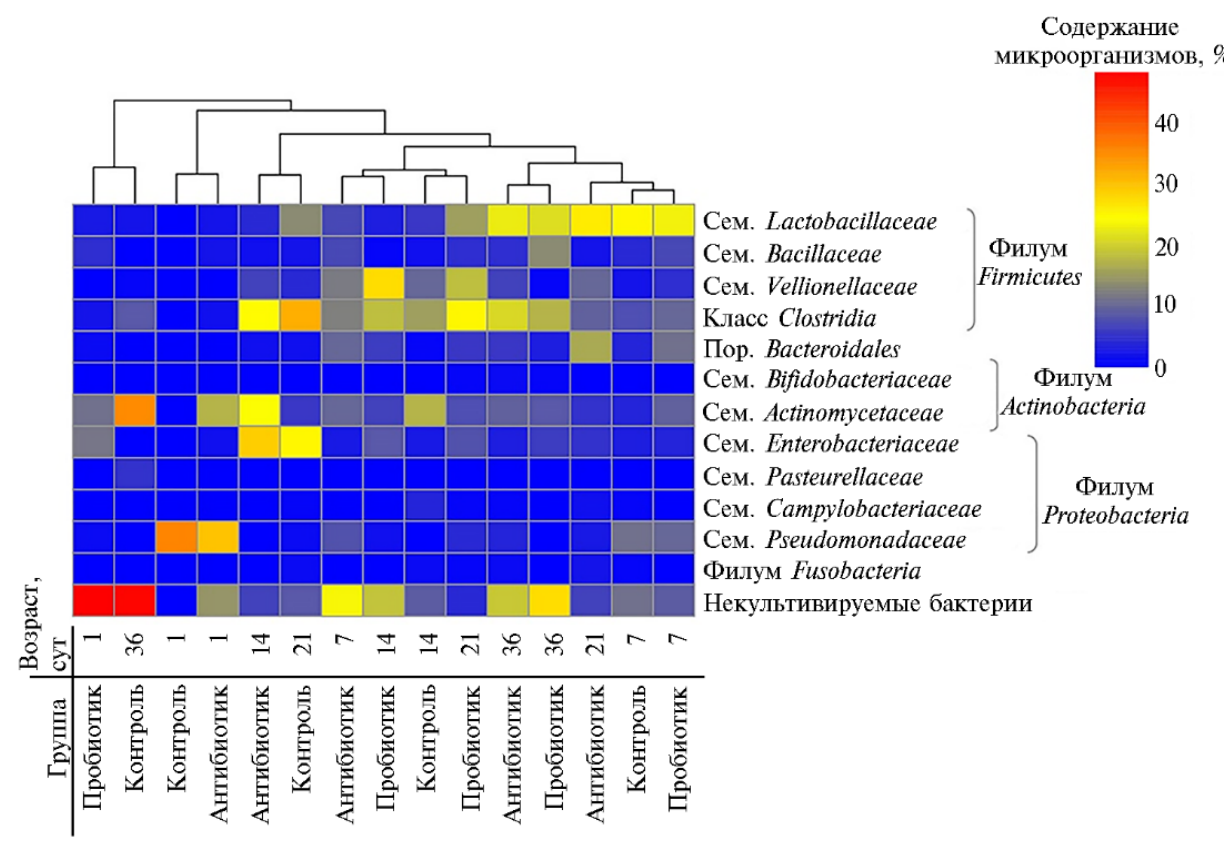

Рис. 2. Кластерный анализ и тепловая карта бактериального сообщества слепых отростков кишечника цыплят-бройлеров кросса Cobb 500 в возрасте 1, 7, 14, 21 и 36 сут в группах, получавших основной рацион (контроль), рацион с добавлением антибиотика Stafac ${ }^{\circledR} 110$ (антибиотик) или рацион с кормовой добавки Целлобактерин ${ }^{\circledR}-\mathrm{T}$ с пробиотическими свойствами, содержащей $\mathrm{Ba}$ cillus subtilis (пробиотик) ( $n=3, M \pm \mathrm{SEM}$, анализ методом количественной ПЦР; виварий, ФГНИУ Всероссийский научно-исследовательский ветеринарный институт птицеводства, г. Санкт-Петербург, 2014 год).

Вывод о быстром становлении микрофлоры ЖКТ птиц подтвердили результаты кластерного анализа (рис. 2). Видно, что в обособленный кластер выделились группы с применением пробиотика в 1-е сут выращивания и контрольный вариант, включающий взрослых бройлеров на 36-е сут.

В микрофлоре химуса слепых отростков кишечника цыплят на уровне филумов доминировали два таксона - Firmicutes и Proteobacteria (см. рис. 2). Менее обильными были филумы Actinobacteria, Bacteroidetes и Fusobacteria. Ранее другие исследователи сообщали (34), что наиболее распространенные филотипы миркоорганизмов слепой кишки принадлежат к филумам Firmicutes (44-55 \%) (это согласуется с нашими результатами) и Bacteroidetes (22-42 \%), а менее представлены таксоны Actinobacteria, Chlorobi, Deferribacteres, Fusobacteria, Verrucomicrobia и Proteobacteria (последние доминировали в нашем опыте). Выявленный нами факт доминирования среди филума Firmicutes бактерий семейств Lactobacillaceae, Bacillaceae, Vellionellaceae и класcа Clostridia позволяет предположить, что микробиота слепых отростках кишечника играет важную роль в переваривании некрахмалистых полисахаридов, связанных с синтезом короткоцепочечных жирных кислот, в 
вытеснении патогенной микрофлоры через продукцию бактериоцинов, а также в снижения рН химуса благодаря синтезу органических кислот (35).

В обособленные кластеры выделились разные варианты (контроль и опыт) на 7-е и 36-е сут выращивания. Это свидетельствует о более выраженном влиянии возраста птиц на состав микрофлоры по сравнению с использованными добавками.

Тем не менее детальный анализ изменения численности ряда таксонов продемонстрировал повышение обилия бактерий класcа Clostridia (среди них встречаются формы, участвующие в расщеплении клетчатки кормов) при включении в рацион антибиотика $\operatorname{Stafac}^{\circledR} 110(\mathrm{p} \leq 0,05)$ и пробиотика $B$. subtilis $(\mathrm{p} \leq 0,05)$ по сравнению с контролем. Подобная тенденция сохранялась на протяжении всего выращивания цыплят (исключая 21-е сут). Наибольшую разницу отмечали на 36-е сут, когда доля бактерий класcа Clostridia в группе, получавшей антибиотик, была на 12,7 \% больше, чем в контроле $(\mathrm{p} \leq 0,01)$, получавшей $B$. subtilis - на $8,8 \%$ больше $(\mathrm{p} \leq 0,05)$. Это важный вывод, имеющий большое практическое значение, поскольку переваривание целлюлозы в кишечнике птиц - исключительно микробиологический процессе в связи с отсутствием у макроорганизма собственных целлюлаз. В 2013 году D. Stanley с соавт. (36) с помощью пиросеквенирования области V3 гена $16 \mathrm{~S}$ рРНК обнаружили, что увеличение численности микробных групп в ЖКТ птиц, в том числе целлюлозолитиков Clostridium islandicum и Ruminococcus sp., связано с ростом продуктивности. Приведенные нами результаты перекликаются с данными метагеномного анализа микробиоты слепой кишки у 42-суточных бройлеров кросca Ross, у которых в этом отделе кишечника выявили многочисленные ферменты, разлагающие полисахариды и олигосахариды (37).

Тенденция увеличения численности других важных представителей Firmicutes - бактерий семейства Vellionellaceae наблюдалась практически во все сроки при применении препарата Stafac ${ }^{\circledR} 110(\mathrm{p} \leq 0,05)$ и B. subtilis $(\mathrm{p} \leq 0,05)$ по сравнению с группой без добавок. Этот вывод также имеет важное значение, поскольку известно, что в результате деятельности представителей семейства Vellionellaceae в слепых отростках происходит накопление короткоцепочечных жирных кислот, которые в дальнейшем усваиваются хозяином (38). Известно, что в слепой кишке птиц летучие жирные кислоты (ЛЖК) абсорбируются через эпителий посредством пассивной диффузии и вовлекаются в различные метаболические пути (39). До 95 \% ЛЖК, продуцируемых в процессе микробной ферментации углеводов (40, $41)$, используются хозяином, обеспечивая до $30 \%$ от общей потребности в энергии. Жвачные животные получают практически $100 \%$ необходимой энергии в результате деятельности рубцового микробиома (42). ЛЖК используются как источник энергии и углерода. Кроме того, они воздействуют на кровоток, стимулируют рост и пролиферацию энтероцитов и регулируют выработку муцина, влияя на иммунный ответ кишечника (39). Имеются подтверждения того, что эти соединения активируют иммунитет макроорганизма, оказывая влияние на экспрессию генов Il1 $\beta$, TNFa, хемокинов и генов иммунного барьера (43). Ранее при анализе микробного содержимого слепых отростков кишечника птиц находили гены, ассоциированные с продукцией бутирата с участием 3-гидроксибутирил-КоА-дегидрогеназы, фосфат-бутирилтрансферазы и бутираткиназы (37). Кроме того, было обнаружено присутствие ацетат-КоА-трансферазы, ответственной за синтез ацетата, и кластеров генов, которые кодируют бета-, гамма- и дельта-субъединицы метилмалонил-КоА-декарбоксилазы, участвующей в образовании пропионата (37). Также в слепых отростках кишечника идентифицированы 
гены 12 гидрогеназ, продуцируемых преимущественно бактериями рода Megamonas, которые принадлежат к семейству Vellionellaceae. Авторы предположили, что эти гидрогеназы могут служить акцепторами водорода, способствуя образованию сукцината (37).

Среди бактерий филума Proteobacteria доминировали семейства Enter-

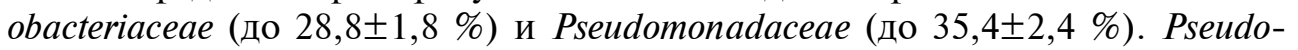
monas sp. ранее также обнаруживались в ЖКТ птиц (5). Большую представленность семейства Pseudomonadaceae в контроле и при применении антибиотика Stafac ${ }^{\circledR} 110$ отмечали у цыплят в 1-е и на 7-е сут (соответственно при $\mathrm{p} \leq 0,001$ и $\mathrm{p} \leq 0,05)$ по сравнению с более взрослой птицей. Многие бактерии семейства Pseudomonadaceae способны гидролизовать фитат и разлагать крахмал, однако следует отметить, что вид Pseudomonas aeruginosa вызывает омфалит - опасное заболевание, которое становится частой причиной смерти птиц в 1-14-суточном возраста. Этот вид устойчив к сульфизоксазолу, цефтиофуру, пенициллину, линкомицину, бацитрацину, окситетрациклину, эритромицину, налидиксовой кислоте и тетрациклину (44).

Среди филума Actinobacteria доминировали бактерии семейства Acti-

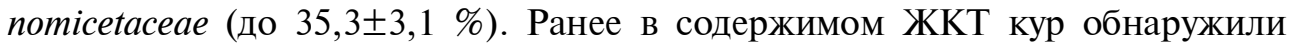
значительное количество метагеномных последовательностей, кодирующих эндоглюканазы, обычно синтезируемые представителями этой таксономической группы, которые разлагают полимеры, в частности целлюлозу и ксилан (37). В нашем эксперименте представленность бактерий семейства $A c$ tinomicetaceae была выше, чем в контроле, у цыплят 1-14-суточного возраста при применении антибиотика $(\mathrm{p} \leq 0,05)$ и 1 - и 7-суточного возраста - при его замене пробиотиком $(\mathrm{p} \leq 0,05)$.

Выявление и изучение патогенных бактерий в микробиоте цыплятбройлеров важно для здоровья как птицы, так и для человека. Следует обратить внимание на тот факт, что в нашем опыте у цыплят в слепых отростках кишечника выявлялись бактерии семейства Campylobacteriaceae. Желудочно-кишечные инфекции у людей, вызванные представителем этого семейства Campylobacter, главным образом связаны с потреблением продуктов из домашней птицы (45). Применение антибиотика Stafac ${ }^{\circledR} 110$ и штамма B. subtilis оказало достоверное влияние на снижение обилия этих микроорганизмов в кишечнике на 14-е сут выращивания (различия с контролем статистически значимы при $\mathrm{p} \leq 0,05)$. У кур среди описанных ранее таксонов, которые могут вызывать заболевания у людей, можно выделить Campylobacter (главным образом Campylobacter jejuni и C. coli), Salmonella enterica, Escherichia coli и Clostridium perfringens (46).

Результаты, свидетельствующие о нормализации микрофлоры домашней птицы при введении в рацион пробиотических штаммов бактерий, многократно подтверждены $(44,47,48)$. В отношении микробиоты кишечника человека сформировалось устойчивое мнение, что большинство известных антибиотиков подавляют не только патогенную, но и комменсальную микрофлору. В нашем исследовании и в работах других авторов введение в рацион птиц вирджиниамицина позитивно повлияло на представителей кишечной нормофлоры. Так, в 2012 году было продемонстрировано увеличение численности кишечных лактобактерий у бройлеров под влиянием вирджиниамицина (49). Двумя годами позже сообщалось (47), что вирджиниамицин значительно снижал численность E. coli в кишечнике цыплят-бройлеров на 42-е сут выращивания и способствовал повышению обилия бактерий рода Lactobacillus по сравнению с контрольной группой.

Сравнение зоотехнических показателей (табл. 1) выявило достоверное $(\mathrm{p}=0,046)$ увеличение живой массы у 36-суточных курочек, в рацион 
которых вводили антибиотик Stafac ${ }^{\circledR} 110$. Подобного эффекта у петушков мы не отмечали в течение всего периода выращивания. Ранее также были описаны половые различия в реакции на $\operatorname{Stafac}^{\circledR} 110$ у бройлеров кросса Cobb 500 в 36-суточном возрасте, но при этом больший прирост живой массы был характерен для петушков, тогда как у курочек этого не наблюдалось (50). Показано, что главный механизм позитивного действия антибиотиков связан с угнетением патогенной микрофлоры и, как следствие, снижением количества продуцируемых ею токсичных метаболитов, особенно продуктов распада аммиака и желчи (51), что, вероятно, наблюдалось и в нашем эксперименте, судя по восстановлению состава микрофлоры. Кроме того, существует мнение, что позитивный эффект от антибиотиков связан с увеличением доступности для макроорганизма питательных веществ в кишечнике и повышением усвояемости белка рациона (51). Мы также не выявили достоверных различий между группами по живой массе курочек до 21 сут выращивания.

1. Возрастная динамика зоотехнических показателей у цыплят-бройлеров кросса Cobb 500 при добавлении в основной рацион (контроль) кормового антибиотика (Stafac $\left.{ }^{\circledR} 110\right)$ или пробиотика (Целлобактерин ${ }^{\circledR}-\mathrm{T}$, содержащий Bacillus subtilis) ( $n=60, M \pm$ SEM, виварий, ФГНИУ Всероссийский научно-исследовательский ветеринарный институт птицеводства, г. Санкт-Петербург, 2014 год)

\begin{tabular}{|c|c|c|c|}
\hline \multirow{2}{*}{ Показатель } & \multicolumn{3}{|c|}{ Группа } \\
\hline & контроль & Stafac $^{\circledR} 110$ & B. subtilis \\
\hline Сохранность поголовья, \% & 97,1 & 100,0 & 100,0 \\
\hline \multicolumn{4}{|l|}{ Живая масса, г: } \\
\hline 1-суточные, & $45,1 \pm 0,4^{\mathrm{a}}$ & $45,1 \pm 0,3^{a}$ & $45,1 \pm 0,3^{\mathrm{a}}$ \\
\hline 14-суточные & $392,4 \pm 7,2^{\mathrm{a}}$ & $412,7 \pm 6,7^{\mathrm{a}}$ & $410,5 \pm 6,9^{\mathrm{a}}$ \\
\hline 21-суточные & $786,5 \pm 10,4^{\mathrm{a}}$ & $825,2 \pm 9,9^{a}$ & $820,54 \pm 10,0^{\mathrm{a}}$ \\
\hline \multicolumn{4}{|l|}{ 36-суточные } \\
\hline в среднем по поголовью & 1989,0 & 2089,9 & 2080,3 \\
\hline петушки & $2132,2 \pm 38,1^{\mathrm{a}}$ & $2243,5 \pm 31,3^{\mathrm{a}}$ & $2233,1 \pm 32,9^{a}$ \\
\hline курочки & $1845,8 \pm 20,9 \mathrm{a}$ & $1936,4 \pm 17,9^{b}$ & $1927,5 \pm 19,4 \mathrm{a}$ \\
\hline Среднесуточный прирост живой массы, г & $55,5 \pm 2,5^{\mathrm{a}}$ & $58,4 \pm 2,2^{\mathrm{a}}$ & $58,2 \pm 3,4^{\mathrm{a}}$ \\
\hline Расход корма на 1 гол. за весь период, кг & $3,5 \pm 0,2^{\mathrm{a}}$ & $3,6 \pm 0,2^{\mathrm{a}}$ & $3,6 \pm 0,2^{\mathrm{a}}$ \\
\hline Расход корма на 1 кг прироста живой массы, кг & $1,8 \pm 0,1^{\mathrm{a}}$ & $1,7 \pm 0,1^{\mathrm{a}}$ & $1,7 \pm 0,2^{\mathrm{a}}$ \\
\hline
\end{tabular}

2. Переваримость и использование питательных веществ 28-36-суточными цыплятами-бройлерами кросса Cobb 500 при добавлении в основной рацион (контроль) кормового антибиотика $\left(\operatorname{Stafac}^{\circledR} 110\right)$ или пробиотика (Целлобактерин ${ }^{\circledR}$-Т, содержащий Bacillus subtilis) ( $n=6, M \pm \mathrm{SEM}$, виварий, ФГНИУ Всероссийский научно-исследовательский ветеринарный институт птицеводства, г. Санкт-Петербург, 2014 год)

\begin{tabular}{|c|c|c|c|}
\hline \multirow{2}{*}{ Показатель } & \multicolumn{3}{|c|}{ Группа } \\
\hline & контроль & Stafac $^{\circledR} 110$ & B. subtilis \\
\hline \multicolumn{4}{|c|}{ Перев в ри мость, $\%$} \\
\hline Белок & $90,8 \pm 4,9^{a}$ & $91,9 \pm 5,3^{\mathrm{a}}$ & $91,4 \pm 5,2^{\mathrm{a}}$ \\
\hline Жир & $80,1 \pm 3,8^{\mathrm{a}}$ & $82,3 \pm 5,5^{\mathrm{a}}$ & $81,7 \pm 4,6^{\mathrm{a}}$ \\
\hline \multirow[t]{2}{*}{ Клетчатка } & $11,5 \pm 0,6^{\mathrm{a}}$ & $13,8 \pm 0,4^{b}$ & $18,6 \pm 0,5^{c}$ \\
\hline & \multicolumn{3}{|c|}{ Испполь зо в а н и е, \% } \\
\hline Азот & $53,5 \pm 2,6^{\mathrm{a}}$ & $55,2 \pm 3,2^{\mathrm{a}}$ & $54,6 \pm 2,8^{\mathrm{a}}$ \\
\hline Кальций & $46,0 \pm 2,5^{\mathrm{a}}$ & $46,9 \pm 2,8^{a}$ & $46,6 \pm 2,1^{\mathrm{a}}$ \\
\hline Фосфор & $38,1 \pm 1,7^{\mathrm{a}}$ & $39,5 \pm 2,1^{\mathrm{a}}$ & $39,1 \pm 1,9^{\mathrm{a}}$ \\
\hline
\end{tabular}

Установлено (см. табл. 1), что антибиотик Stafac ${ }^{\circledR} 110$ и штамм B. subtilis не оказывали достоверного влияния на расход корма.

Полученные нами результаты совпадают с известными данными. Так, группа ученых (52) изучала эффективность пробиотика Lacto G на ос- 
нове лактобактерий при введении в рацион цыплят-бройлеров на фоне искусственного заражения птиц возбудителем кокцидиоза Eimeria tenella. Полученные результаты показали, что, несмотря на снижение инфицированности патогеном при применении пробиотика, не было выявлено положительного влияния препарата на показатели прироста живой массы и конверсию корма.

В нашем опыте (табл. 2) переваримость клетчатки в группе с интродукцией в рацион штамма B. subtilis была на 7,1 \% выше, чем в контроле $(\mathrm{p}=0,0027)$, антибиотика - на $2,3 \%$ выше, чем в контроле $(\mathrm{p}=0,047)$. Вероятно, это связано с восстановлением структуры микробиома кишечника у цыплят из опытных групп и ростом численности микроорганизмов, проявляющих целлюлозолитическую активность, например бактерий рода Ruminococcus, а также целлюлозолитиков из рода Clostridium (53).

Судя по результатам детального анализа микробного сообщества кишечника птиц, в слепых отростках в основном доминировала микробиота, играющая важную роль в переваривании некрахмалистых полисахаридов, участвующая в синтезе короткоцепочечных жирных кислот и вытеснении патогенной микрофлоры с помощью синтеза бактериоцинов. Очевидно, что микробиом птиц, который оказывает столь выраженное влияние на функционирование макроорганизма, нуждается в корректировке и поддержании. На сегодняшний момент получены данные как о положительном, так и об отрицательном влиянии антибиотикотерапии на состав микробиоты кишечника птиц. Наше исследование выявило преимущественно позитивное влияние кормового антибиотика $\operatorname{Stafac}^{\circledR} 110$ на структуру микробиома: возросло содержание целлюлозолитических форм и бактерий, участвующих в синтезе органических кислот, вовлекаемых макроорганизмом в важнейшие процессы метаболизма. Однако сходные данные о положительных изменениях в структуре микробного сообщества были получены и при интродукции пробиотического штамма $B$. subtilis. Эти результаты могут представлять большой практический интерес в связи существующим в настоящее время потребительским протестом и государственными ограничениями в отношении использования антибиотиков в птицеводстве и животноводстве. Так, распоряжением Правительства России № 604-р от 30.03.2019 в рамках государственной Стратегии предупреждения распространения антимикробной резистентности в Российской Федерации до 2030 года с 2020 года запрещено применять ветеринарные противомикробные препараты не в лечебных целях. За нарушение этого запрета ожидается введение административной ответственности. Кроме того, с 2020 года должно регулироваться использование противомикробных препаратов при изготовлении кормов (с соответствующими изменениями в существующем законодательстве).

На наш взгляд, замена антибиотиков в кормах на пробиотики в условиях отказа от антибактериальных средств вполне реальна, но требует дополнительных исследований для понимания молекулярных механизмов положительного влияния антибиотиков и пробиотиков не только на микрофлору толстого кишечника, но и на другие отделы кишечника. Интересно было бы в дальнейшем сравнить влияние кормовых и лекарственных антибиотиков на структуру микробиома цыплят, а также оценить изменения в микрофлоре ЖКТ взрослой птицы (родительского стада и несушек) под влиянием антибиотиков или пробиотиков.

Таким образом, полученные нами результаты указывают на то, что интродукция штамма Bacillus subtilis в желудочно-кишечный тракт цыплятбройлеров обеспечивает более быстрое становление кишечной микрофлоры (уже в 1-е сут жизни) по сравнению с вариантами без добавок, а 
также с введением антибиотика $\operatorname{Stafac}^{\circledR} 110$ на основе вирджиниамицина. На 14-е сут вырашивания кормовой антибиотик и пробиотический штамм снизили в кишечнике (по сравнению с контролем) обилие микроорганизмов семейства Campylobacteriaceae, среди которого могут встречаться возбудители гастроэнтеритов. Кормовой антибиотик Stafac ${ }^{\circledR} 110$ повысил живую массу у 36-суточных курочек, но не у петушков (несмотря на восстановление у них микрофлоры). Переваримость клетчатки при интродукции штамма B. subtilis повышалась по сравнению с контролем и вариантом с введением антибиотика, что может быть связано с деятельностью целлюлозолитических микроорганизмов. Антибиотик $\operatorname{Stafac}^{\circledR} 110$ и пробиотический штамм B. subtilis не оказали достоверного влияния на расход корма. Включение пробиотического штамма бактерий $B$. subtilis в составе Целлобактерина ${ }^{\circledR}-\mathrm{T}$ в рацион цыплят-бройлеров для восстановления микрофлоры и повышения переваримости клетчатки может быть эффективной альтернативой кормовому антибиотику Stafac ${ }^{\circledR} 110$ на основе вирджиниамицина.

\section{ЛИТЕРАТУРА}

1. Phillips I., Casewell M., Cox T., De Groot B., Friis C., Jones R., Nightingale C., Preston R., Waddell J. Does the use of antibiotics in food animals pose a risk to human health? A critical review of published data. Journal of Antimicrobial Chemotherapy, 2004, 53(1): 28-52 (doi: $10.1093 / \mathrm{jac} / \mathrm{dkg} 483)$.

2. Gong J., Yin. F., Hou Y., Yin Y. Chinese herbs as alternatives to antibiotics in feed for swine and poultry production: potential and challenges in application. Canadian Journal of Animal Science, 2014, 94(2): 223-242 (doi: 10.4141/cjas2013-144).

3. Humphreys G., Fleck F. United Nations meeting on antimicrobial resistance. Bull. World Health Organ., 2016, 94(9): 638-639 (doi: 10.2471/BLT.16.020916).

4. Onrust L., Ducatelle R., Driessche K.V., Maesschalck C., Vermeulen K., Haesebrouck F., Van Immerssel F. Steering endogenous butyrate production in the intestinal tract of broilers as a tool to improve gut health. Frontiers in Veterinary Science, 2015, 2: 75 (doi: 10.3389/fvets.2015.00075).

5. Borda-Molina D., Seifert J., Camarinha-Silva A. Current perspectives of the chicken gastrointestinal tract and its microbiome. Computational and Structural Biotechnology Journal, 2018, 16: 131139 (doi: 10.1016/j.csbj.2018.03.002).

6. Kohl K.D. Diversity and function of the avian gut microbiota. Journal of Comparative Physiology B-Biochemical Systems and Environmental Physiology, 2012, 182(5): 591-602 (doi: 10.1007/s00360012-0645-z).

7. Lindberg R., Jarnheimer P.A., Olsen B., Johansson M., Tysklind M. Determination of antibiotic substances in hospital sewage water using solid phase extraction and liquid chromatography/mass spectrometry and group analogue internal standards. Chemosphere, 2004, 57(10): 1479-1488 (doi: 10.1016/j.chemosphere.2004.09.015).

8. Van Der Waaij D., Nord C.E. Development and persistence of multi-resistance to antibiotics in bacteria; an analysis and a new approach to this urgent problem. International Journal of Antimicrobial Agents, 2000, 16(3): 191-197 (doi: 10.1016/S0924-8579(00)00227-2).

9. Teirlynck E., De Gussem M., Marlen M., Vancraeynest D., Haesebrouck F., Ducatelle R., Van Immerseel F. Morphometric evaluation of "dysbacteriosis" in broilers. Avian Pathology, 2013, 40(2): 139-144 (doi: 10.1080/03079457.2010.543414).

10. Thomke S., Elwinger K. Growth promotants in feeding pigs and poultry. III. Alternatives to antibiotic growth promotants. Annales De Zootechnie, 1998, 47(4): 245-271 (doi: 10.1051/animres:19980402).

11. Verstegen M.W.A., Williams B.A. Alternatives to the use of antibiotics as growth promoters for monogastric animals. Animal Biotechnology, 2002, 13(1): 113-127 (doi: 10.1081/ABIO-120005774).

12. Yang Y., Iji P.A., Choct M. Dietary modulation of gut microflora in broiler chickens: a review of the role of six kinds of alternatives to in feed antibiotics. World's Poultry Science Journal, 2009, 65(1): 97-114 (doi: 10.1017/S0043933909000087).

13. Li Z., Wang W., Liu D., Guo Y. Effects of Lactobacillus acidophilus on gut microbiota composition in broilers challenged with Clostridium perfringens. PLOS ONE, 2017, 12(11): 1-16 (doi: 10.1371/journal.pone.0188634).

14. Maces-Lázaro R., Van Diemen P.M., Pin C., Mayer M.J., Stevens M.P., Narbad A. Administration of Lactobacillus johnsonii FI9785 to chickens affects colonisation by Campylobacter jejuni and the intestinal microbiota. British Poultry Science, 2017, 58(4): 373-381 (doi: 10.1080/00071668.2017.1307322). 
15. Macfarlane S. Antibiotics treatment and microbes in the gut. Environmental Microbiology, 2014, 16(4): 919-924 (doi: 10.1111/1462-2920.12399).

16. Ferrer M., Martins dos Santos V.A., Ott S.J., Moya A. Gut microbiota disturbance during antibiotic therapy: a multi-omic approach. Gut Microbes, 2014, 5(1): 64-70 (doi: 10.4161/gmic.27128).

17. Robinson C.J., Young V.B. Antibiotic administration alters the community structure of the gastrointestinal microbiota. Gut Microbes, 2010, 1(4): 279-284 (doi: 10.4161/gmic.1.4.12614).

18. Ji S., Jiang T., Yan H., Guo C., Liu J., Su H., Alugongo G.M., Shi H., Wang Y., Cao Z., Li S. Ecological restoration of antibiotic-disturbed gastrointestinal microbiota in foregut and hindgut of cows. Frontiers in Cellular and Infection Microbiology, 2018, 8: 79 (doi: 10.3389/fcimb.2018.00079).

19. Lin J., Hunkapiller A.A., Layton A.C., Chang Y.J., Robbins K.R. Response of intestinal microbiota to antibiotic growth promoters in chickens. Foodborne Pathogens and Disease, 2013, 10(4): $331 \mathrm{e} 7$ (doi: 10.1089/fpd.2012.1348).

20. Danzeisen J.L., Kim H.B., Isaacson R.E., Tu Z.J., Johnson T.J. Modulations of the chicken cecal microbiome and metagenome in response to anticoccidial and growth promoter treatment. PLoS ONE, 2011, 6: e27949 (doi: 10.1371/journal.pone.0027949).

21. Lee K.W., Ho Hong Y., Lee S.H., Jang S.I., Park M.S., Bautista D.A., Ritter G.D., Jeong W., Jeoung H.Y., An D.J., Lillehoj E.P., Lillehoj H.S. Effects of anticoccidial and antibiotic growth promoter programs on broiler performance and immune status. Research in Veterinary Science, 2012, 93(2): 721-728 (doi: 10.1016/j.rvsc.2012.01.001).

22. Zhou H., Gong J., Brisbin J.T., Yu H., Sanei B., Sabour P., Sharif S. Appropriate chicken sample size for identifying the composition of broiler intestinal microbiota affected by dietary antibiotics, using the polymerase chain reaction-denaturing gradient gel electrophoresis technique. Poultry Science, 2007, 86(12): 2541-2549 (doi: 10.3382/ps.2007-00267).

23. Gao P., Ma C., Sun Z., Wang L., Huang S., Su X., Xu J., Zhang H. Feed-additive probiotics accelerate yet antibiotics delay intestinal microbiota maturation in broiler chicken. Microbiome, 2017 5(1): 91 (doi: 10.1186/s40168-017-0315-1).

24. Лаптев Г.Ю. Исследование бактериального сообщества рубца коров с помощью T-RFLPанализа. Молочное и мясное скотоводство, 2010, 3: 16-18.

25. Tannock G.W., Munro K., Harmsen H.J., Welling G.W., Smart J., Gopal P.K. Analysis of the fecal microflora of human subjects consuming a probiotic product containing Lactobacillus rhamnosus DR20. Applied and Environmental Microbiology, 2000, 66(6): 2578-2588 (doi: 10.1128/AEM.66.6.2578-2588.2000).

26. RDocumentation. pheatmap. A function to draw clustered heatmaps. Режим доступа: https://www.rdocumentation.org/packages/pheatmap/versions/1.0.12/topics/pheatmap. Дата обращения 08.02.2020.

27. Murtagh F., Legendre P., Classif J. Ward's hierarchical agglomerative clustering method: which algorithms implement Ward's criterion? Journal of Classification, 2014, 31(3): 274-295 (doi: 10.1007/s00357-014-9161-z).

28. Брюс П., Брюс Э. Практическая статистика для специалистов Data Science. СПб, 2018.

29. Verzani J. Getting started with RStudio. O'Reilly Media, Sebastopol, 2011.

30. RStudio. Режим доступа: https://rstudio.com. Без даты.

31. Rinttilä T., Apajalahti J. Intestinal microbiota and metabolites - implications for broiler chicken health and performance. Journal of Applied Poultry Research, 2013, 22: 647-658 (doi: 10.3382/japr.2013-00742).

32. Jeurissen S.H.M., Janse E.M., Koch G., De Boer G.F. Postnatal development of mucosa-associated lymphoid tissues in chickens. Cell and Tissue Research, 1989, 258(1): 119-124.

33. Wang L., Lilburn M., Yu Z. Intestinal microbiota of broiler chickens as affected by litter management regimens. Frontiers in Microbiology, 2016, 7: 593 (doi: 10.3389/fmicb.2016.00593).

34. Qu A., Brulc J.M., Wilson M.K., Law B.F., Theoret J.R., Joens L.A. Comparative metagenomics reveals host specific metavirulomes and horizontal gene transfer elements in the chicken cecum microbiome. PLoS ONE, 2008, 3(8): e2945 (doi: 10.1371/journal.pone.0002945).

35. Jyzefiak D., Rutkowski A., Martin S.A. Carbohydrate fermentation in the avian ceca: a review. Animal Feed Science and Technology, 2004, 113(1-4): 1-15 (doi: 10.1016/j.anifeedsci.2003.09.007).

36. Stanley D., Geier M.S., Denman S.E., Haring V.R., Crowley T.M., Hughes R.J., Moore R.J. Identification of chicken intestinal microbiota correlated with the efficiency of energy extraction from feed. Veterinary Microbiology, 2013, 164(1-2): 85-92 (doi: 10.1016/j.vetmic.2013.01.030).

37. Sergeant M.J., Constantinidou C., Cogan T.A., Bedford M.R., Penn C.W., Pallen M.J. Extensive microbial and functional diversity within the chicken cecal microbiome. PLoS ONE, 2014, 9(3): e91941 (doi: 10.1371/journal.pone.0091941).

38. McWhorter T.J., Caviedes-Vidal E., Karasov W.H. The integration of digestion and osmoregulation in the avian gut. Biological Reviews of the Cambridge Philosophical Society, 2009: 84(4): 533565 (doi: 10.1111/j.1469-185X.2009.00086.x).

39. Tellez G., Higgins S.E., Donoghue A.M., Hargis B.M. Digestive physiology and the role of microorganisms. Journal of Applied Poultry Research, 2006, 15(1): 136-144. 
40. Cummings J.H., Pomare E.W., Branch W.J., Naylor C.P., Macfarlane G.T. Short chain fatty acids in human large intestine, portal, hepatic and venous blood. Gut, 1987, 28(10): 1221-1227 (doi: 10.1136/gut.28.10.1221).

41. van Der Wielen P.W., Biesterveld S., Notermans S., Hofstra H., Urlings B.A.P., van Knapen F. Role of volatile fatty acids in development of the cecal microflora in broiler chickens during growth. Applied and Environmental Microbiology, 2000, 66(6): 2536-2540 (doi: 10.1128/aem.66.6.25362540.2000).

42. Hungate R.E. The rumen and its microbes. Academic Press, NewYork, 1966.

43. Zhan K., Gong X., Chen Y., Jiang M., Yang T., Zhao G. Short-chain fatty acids regulate the immune responses via $\mathrm{G}$ protein-coupled receptor 41 in bovine rumen epithelial cells. Frontiers in Immunology, 2019, 10: 2042 (doi: 10.3389/fimmu.2019.02042).

44. Walker S.E., Sander J.E., Cline J.L., Helton J.S., Characterization of Pseudomonas aeruginosa isolates associated with mortality in broiler chicks. Avian Diseases, 2002, 46(4): 1045-1050 (doi: 10.1637/0005-2086(2002)046[1045:COPAIA]2.0.CO;2).

45. Wegener H.C., Hald T., Wong D.L.F., Madsen M., Korsgaard H., Bager F., Gerner-Smidt P., Mwlbak K. Salmonella control programs in Denmark. Emerging Infectious Diseases journal, 2003, 9(7): 774-780 (doi: 10.3201/eid0907.030024).

46. Oakley B.B., Lillehoj H.S., Kogut M.H., Kim W.K., Maurer J.J., Pedroso A., Lee M.D., Collett S.R., Johnson T.J., Cox N.A. The chicken gastrointestinal microbiome. FEMS Microbiology Letters, 2014, 360(2): 100-112 (doi: 10.1111/1574-6968.12608).

47. Ramiah S.K., Zulkifli I., Rahim N.A., Ebrahimi M., Meng G.Y. Effects of two herbal extracts and virginiamycin supplementation on growth performance, intestinal microflora population and Fatty Acid composition in broiler chickens. Asian-Australasian Journal of Animal Sciences, 2014, 27(3): 375-382 (doi: 10.5713/ajas.2013.13030).

48. Forte C., Moscati L., Acuti G., Mugnai C., Franciosini M.P., Costarelli S., Cobellis G., TrabalzaMarinucci M. Effects of dietary Lactobacillus acidophilus and Bacillus subtilis on laying performance, egg quality, blood biochemistry and immune response of organic laying hens. Journal of Animal Physiology and Animal Nutrition, 2016, 100(5): 977-987 (doi: 10.1111/jpn.12408).

49. Zulkifli I., Hashemi S.R., Somchit M.N., Zunita Z., Loh T.C., Soleimani A.F., Tang S.C. Effects of Euphorbia hirta and virginiamycin supplementation to the diet on performance, digestibility, and intestinal microflora population in broiler chickens. Archiv für Geflugelkünde, 2012, 76(1): 6-12.

50. Андрианова Е.Н., Егоров И.А., Присяжная Л.М., Ахметова Л Т., Сибгатуллин Ж.Ж., Слесаренко Н.А., Лаптев Г.Ю. Добавка Винивет на основе продуктов пчеловодства как альтернатива кормовым антибиотикам в комбикормах для цыплят-бройлеров: бактерицидный и биостимулирующий эффект применения. Сельскохозяйственная биология, 2016, 51(2): 213222 (doi: 10.15389/agrobiology.2016.2.213rus).

51. Niewold T.A. The nonantibiotic anti-inflammatory effect of antimicrobial growth promoters, the real mode of action? A hypothesis. Poultry Science, 2007, 86(4): 605-609 (doi: 10.1093/ps/86.4.605).

52. Abu-Akkada Somaia S., Awad Ashraf M. Protective effects of probiotics and prebiotics on Eimeria Tenella-infected broiler chickens. Pakistan veterinary journal, 2015, 35(4): 446-450.

53. Yadav S., Jha R. Strategies to modulate the intestinal microbiota and their effects on nutrient utilization. performance and health of poultry. Journal of Animal Science and Biotechnology, 2019, 10: 2 (doi: 10.1186/s40104-018-0310-9).

$10 О О$ «БИОТРОФ+»,

192284 Россия, г. Санкт-Петербург, Загребский б-р, 19, корп. 1, e-mail: tirina@biotrof.ru, georg-laptev@rambler.ru, deniz@biotrof.ru $₫$, ilina@biotrof.ru, filippova@biotrof.ru,bea@biotrof.ru, tarlav1995@biotrof.ru, elena@biotrof.ru, dubrowin.a.v@yandex.ru, novikova@biotтof.ru, timur@biotrof.ru;

2 ФНЦ Всероссийский научно-исследовательский и технологический институт птицеводства РАН, 141311 Россия, Московская обл., г. Сергиев Посад,

ул. Птицеградская, 10,

e-mail: Alena_fisinina@mail.ru
Поступила в редакцию 12 мая 2020 года

Sel'skokhozyaistvennaya biologiya [Agricultural Biology], 2020, V. 55, № 6, pp. 1220-1232

\title{
THE IMPACT OF VIRGINIAMICIN AND PROBIOTICS ON INTESTINAL MICROBIOME AND GROWTH PERFORMANCE TRAITS OF CHICKEN (Gallus gallus L.) BROILERS
}

\author{
D.G. Tyurina ${ }^{1}$, G.Yu. Laptev ${ }^{1}$, E.A. Yildirim ${ }^{1}$, L.A. Ilina ${ }^{1}$, V.A. Filippova ${ }^{1}$, \\ E.A. Brazhnik', N.V. Tarlavin ${ }^{1}$, E.P. Gorfunkel ${ }^{1}$, A.V. Dubrovin ${ }^{1}$, N.I. Novikoval,
}




\title{
T.P. Dunyashev ${ }^{1}$, A.A. Grozina ${ }^{2}$
}

1JSC Biotrof+, 19, korp. 1, Zagrebskii bulv., St. Petersburg, 192284 Russia, e-mail tirina@biotrof.ru, georg-laptev@rambler.ru, deniz@biotrof.ru ( $₫$ corresponding author), ilina@biotrof.ru, filippova@biotrof.ru,bea@biotrof.ru, tarlav1995@biotrof.ru, elena@biotrof.ru, dubrowin.a.v@yandex.ru, novikova@biotrof.ru, timur@biotrof.ru;

${ }^{2}$ Federal Scientific Center All-Russian Research and Technological Poultry Institute RAS, 10, ul. Ptitsegradskaya, Sergiev Posad, Moscow Province, 141311 Russia, e-mail Alena_fisinina@mail.ru

ORCID:

Tyurina D.G. orcid.org/0000-0001-9001-2432

Laptev G.Yu. orcid.org/0000-0002-8795-6659

Yildirim E.A. orcid.org/0000-0002-5846-5105

Ilina L.A. orcid.org/0000-0003-2789-4844

Filippova V.A. orcid.org/0000-0001-8789-9837

Brazhnik E.A. orcid.org/0000-0003-2178-9330

The authors declare no conflict of interests

Received May 12, 2020

\begin{abstract}
Tarlavin N.V. orcid.org/0000-0002-6474-9171
Gorfunkel E.P. orcid.org/0000-0002-6843-8733

Dubrovin A.V. orcid.org/0000-0001-8424-4114

Novikova N.I. orcid.org/0000-0002-9647-4184

Dunyashev T.P. orcid.org/0000-0002-3918-0948

Grozina A.A. orcid.org/0000-0001-9654-7710
\end{abstract}

doi: 10.15389/agrobiology.2020.6.1220eng

\begin{abstract}
Today, there is great interest in the development of environmentally friendly feed additives for poultry farming as a worthy alternative to antibiotics capable of positively modulating the microbiota to control pathogenic microorganisms. However, very few studies have been devoted to comparing the effects of probiotics and antibiotics on the structure of the gut microbiome in broilers. In this study, we compared the composition of the intestinal microbiota and zootechnical parameters in chickens of the Cobb 500 cross during the starter, growth and finishing periods when a probiotic (Bacillus subtilis in the composition of Cellobacterin ${ }^{\circledR}-\mathrm{T}$ ) or an antibiotic (Stafac ${ }^{\circledR} 110$ based on virginiamycin) was added to the diet and showed that the $B$. subtilis strain accelerates the formation of intestinal microflora. The probiotic also reduces the number of microorganisms of the Campylobacteriaceae family which includes many types of gastroenteritis pathogens, and also increases the digestibility of fiber. T-RFLP analysis and qPCR method were used to assess changes in the intestinal microbiota of Cobb 500 broiler chickens fed a Bacillus subtilis-based dietary probiotic and virginiamycin-based dietary antibiotic Stafac ${ }^{\circledR} 110$. On day 14 , the total counts of cecal bacteria, as compared to control, were 9.1 times higher $(\mathrm{p} \leq 0.05)$ in broilers fed Stafac ${ }^{\circledR} 110$, and 54.2 times higher $(\mathrm{p} \leq 0.001)$ when fed B. subtilis preparation. This indicates rapid microbial colonization of gastrointestinal tract of the chickens fed Stafac ${ }^{\circledR} 110$ and B. subtilis. T-RFLP analysis revealed two dominant cecal phyla, Firmicutes and Proteobacteria, while phyla Actinobacteria, Bacteroidetes, and Fusobacteria were less abundant. The taxa are detected which ferment non-starch polysaccharides to produce short-chain fatty acids, inhibit the competing pathogens due to production of bacteriocins, and acidize the chyme as synthesize organic acids. Administration of the dietary antibiotic mostly positively influences the cecal microbiota, e.g., the cellulolytic bacteria and Clostridia forms involved in the synthesis of organic acids became more abundant $(\mathrm{p} \leq 0.05)$. Similar beneficial effects, e.g., an increase in Clostridia counts $(\mathrm{p} \leq 0.05)$ compared to control, occurred when the probiotic strain was administered. On day 14 of rearing, the dietary antibiotic and probiotic reduced abundance of Campylobacteriaceae family comprising gastroenteritis pathogens $(\mathrm{p} \leq 0.05)$ when compared to control. An increase in bodyweight as compared to control (from $1845.8 \pm 20.9$ to $1936.4 \pm 17.9 \mathrm{~g}, \mathrm{p}=0.046$ ) occurred in 36-day-old chickens fed Stafac ${ }^{\circledR} 110$ but not the probiotic strain but not the probiotic strain, despite recovery of gut microbiota in the chickens fed B. subtilis. A $7.1 \%$ increase in fiber digestibility $(\mathrm{p}=0.0027)$ occurred in broilers fed dietary probiotic and a $2.3 \%$ increase $(\mathrm{p}=0.047)$ in those fed the dietary antibiotic, which may be due to the action of cellulolytic microorganisms. Therefore, a dietary B. subtilis-based probiotic which promotes recovery of gut microbiota and increases fiber digestibility in feeds for broiler chickens can be an effective alternative to the virginiamycin-based antibiotic Stafac ${ }^{\circledR} 110$.
\end{abstract}

Keywords: broiler chickens, Cobb 500, probiotic, Bacillus subtilis, Stafac ${ }^{\circledR} 110$, T-RFLP analysis, microbiome, Firmicutes, Proteobacteria, Clostridia, Campylobacteriaceae. 